\title{
Role of Neural Cell Adhesion Molecule and Polysialic Acid in Mouse Circadian Clock Function
}

\author{
Huaming Shen, ${ }^{1}$ Michiko Watanabe, ${ }^{2}$ Henry Tomasiewicz, ${ }^{4}$ Urs Rutishauser, ${ }^{3}$ Terry Magnuson, ${ }^{3}$ and \\ J. David Glass ${ }^{1}$ \\ ${ }^{1}$ Department of Biological Sciences, Kent State University, Kent, Ohio 44242-0001, 2Division of Pediatric Cardiology, \\ Department of Pediatrics, Rainbow Babies and Children Hospital, Case Western Reserve University, Cleveland, Ohio \\ 44106-4955, ${ }^{3}$ Department of Genetics, Case Western Reserve University, Cleveland, Ohio 44106-4955, and \\ ${ }^{4}$ Department of Anatomy and Cell Biology, Emory University, Atlanta, Georgia 30322
}

The suprachiasmatic nuclei (SCN) express the highly polysialylated form of the neural cell adhesion molecule (NCAM) that has been proposed to promote plasticity in the adult brain. To investigate a role for NCAM in SCN circadian clock function, we examined the daily locomotor rhythm of mice homozygous for a mutation, Ncam ${ }^{\text {tm1Cwr }}$, which results in deletion of the NCAM-180 isoform that in brain carries polysialic acid (PSA). Mutant mice entrained well to a $12 \mathrm{hr}$ light/dark cycle but exhibited a significantly shortened free-running period and longer activity duration under constant darkness (DD) than did wild-type mice. By the third week of DD treatment, circadian rhythmicity in the mutant was abolished. Immunocytochemical analyses of the mutant SCN revealed an abnormal number and distribution of vasoactive intestinal polypeptide-producing neurons, suggesting a developmental effect of the mutant phenotype; however, a direct physiological effect of the mutation on clock function was indicated by the fact that removal of PSA from adult wild-type SCN by microinjection of endoneuraminidase shortened the free-running period to a similar extent as in the mutant. Together, these data indicate critical roles for NCAM and PSA in the development and physiology of the mammalian SCN circadian clock.

Key words: neural cell adhesion molecule; polysialic acid; circadian rhythms; suprachiasmatic nucleus; mouse; endoneuraminidase
The suprachiasmatic nuclei $(\mathrm{SCN})$ are the principal site for the generation and entrainment of mammalian circadian rhythms (Rusak, 1977; Rusak and Zucker, 1979; Moore, 1983). The autonomy of the mammalian SCN pacemaker has been demonstrated in studies in which circadian rhythms in SCN neuronal activity persist when these nuclei are isolated surgically from the rest of the brain or cultured in vitro (Inouye and Kawamura, 1979; Green and Gillette, 1982; Earnest and Sladek, 1986). Also, lesions of the SCN disrupt circadian rhythmicity (for the mouse, see Schwartz and Zimmerman, 1991), and this can be restored by transplantation of fetal SCN into SCN-lesioned hosts (Lehman et al., 1987; Earnest et al., 1989). The timing of SCN-generated circadian rhythms is regulated primarily by photic information relayed from the retina to the SCN. This involves two afferent systems: a monosynaptic projection from the retina to the SCN, the retinohypothalamic tract (RHT) (Moore and Lenn, 1972; Pickard, 1982; Youngstrom and Nunez, 1986; Johnson et al., 1988), and an indirect pathway from the intergeniculate leaflet, the geniculohypothalamic tract (Card and Moore, 1989; Zhang and Rusak, 1989). Experiments in animals held under constant darkness (DD) have demonstrated that the phase of pacemakerdriven activity rhythms can be reset by timed light pulses (Daan and Pittendrigh, 1976) and that this involves a cascade of events

\footnotetext{
Received March 5, 1997; revised April 14, 1997; accepted April 17, 1997.

This research was supported by Air Force Office of Scientific Research Grant F49620-93-0086 (J.D.G.) and National Institutes of Health Grants HD18369, EY06107, and NS32779 (U.R.), and HD26722 (T.M.).

Correspondence should be addressed to J. David Glass, Department of Biological Sciences, Kent State University, Kent, OH 44242-0001.

Copyright (C) 1997 Society for Neuroscience 0270-6474/97/175221-09\$05.00/0
}

initiated by RHT-mediated activation of SCN cells (Rea, 1989; Kornhauser et al., 1993).

Recently we reported that the adult hamster SCN express neural cell adhesion molecule (NCAM) in its highly polysialylated form (Glass et al., 1994). This form of NCAM is characterized by long $\alpha 2,8$-linked sialic acid polymers (PSA), which serve to attenuate cell-cell interactions and thereby promote changes in tissue architecture (Rutishauser et al., 1988). For example, PSA-NCAM is abundant in the developing nervous system where it is involved in facilitating cell migration and axon guidance (Rutishauser and Landmesser, 1996). Expression of PSA-NCAM has also been identified in other regions of the adult brain that have the capacity for cellular plasticity. These include the hippocampus, supraoptic nuclei, olfactory bulb, and dentate gyrus (Theodosis et al., 1991; Bonfanti et al., 1992; Le Gal La Salle et al., 1992; Seki and Arai, 1991). Moreover, NCAM-deficient mice have defects in learning (Cremer et al., 1994), and enzymatic removal of PSA from cultured hippocampal slices abolishes long-term potentiation and longterm depression (Muller et al., 1996). In view of this evidence, the possibility exists that polysialylated NCAM is important for regulating plastic cell-cell interactions in the adult SCN.

To investigate a role for NCAM in circadian time keeping, we examined SCN function in mice with a mutation $\left(\mathrm{Ncam}^{\mathrm{tm} 1 \mathrm{Cwr}}\right)$, which in adults results in deletion of the NCAM isoform that carries PSA in the brain (Tomasiewicz et al., 1993). In complementary experiments designed to evaluate the role of the PSA carbohydrate itself in the adult SCN, we also examined the circadian effects of PSA depletion in the SCN region using intra-SCN microinjection of an endoneuramini- 
dase, which specifically removes PSA from the NCAM polypeptide (Rutishauser et al., 1985).

\section{MATERIALS AND METHODS}

\section{Animals}

Nam $^{\text {tm1Cwr }}$ mutant mice were generated using the method of homologous recombination in embryonic stem cells after deletion of NCAM180-specific exon 18 and confirmed with the allele-specific PCR and Southern blot analyses. Details of this procedure are provided in Tomasiewicz et al. (1993). Experiments were conducted on matched homozygous, heterozygous, and wild-type litter mates bred to 93\% 129/ Sv:7\% CF1. Because of limited availability of matched Ncam ${ }^{\text {tm1Cwr }}$ wild types, the experiments involving SCN microinjection of endoneuroaminidase $\mathrm{N}$ (endo N) were carried out using an inbred 129/Sv line.

\section{Activity assessments}

Mice were housed individually in a plastic circular cage in a photoperiodcontrolled environmental chamber with a cage level of illuminance of $\sim 250$ lux. An infrared motion sensor placed overhead and focused at the center of the cage was used to monitor the general locomotor activity of the animals inside the cage. Output from the detectors was collected and integrated with an IBM-compatible computer running Dataquest III data acquisition software (Minimitter). Analyses of rhythm characteristics and graphical output (actograms) were undertaken using Tau software (Minimitter). The free-running period of the locomotor activity rhythm under DD was obtained from the $\chi^{2}$ periodogram averaged over a certain period of time. The duration of the active period was determined as the duration between the initial and final peaks of an animal's subjective nocturnal activity bout that exceeded the mean daily activity level averaged over a given photoperiod treatment. Under constant light conditions [DD or constant light (LL)], the onset of running activity, designated as circadian time 12, was used as the phase reference point for the beginning of subjective night. Activity onset is defined as the first 6 min interval that is (1) coincident with an intensity of running activity that exceeded $10 \%$ of the maximum rate for the day, (2) preceded by a period of at least $4 \mathrm{hr}$ of inactivity, and (3) followed by a period of at least $30 \mathrm{~min}$ of sustained activity.

\section{Immunohistological analyses}

Antibodies. Ascites fluid containing a characterized mouse monoclonal antibody 5A5 (IgM) against $\alpha$-2,8-linked PSA of NCAM was used for immunolabeling of PSA-NCAM (Acheson et al., 1991). The NCAM polypeptide was labeled using a protein-A-purified mouse monoclonal antibody 3F4 (IgG) against brain NCAM. Vasoactive intestinal polypeptide was stained with rabbit IgG anti-VIP (Chemicon, Temecula, CA).

Light microscopic immunostaining. Mice deeply anesthetized with sodium pentobarbital (Nembutal) were perfused intracardially with ice-cold $4 \%$ paraformaldehyde. The brains were removed and immersed in the same fixative overnight at $4^{\circ} \mathrm{C}$. Coronal vibratome sections $(60 \mu \mathrm{m}$ thick) containing the SCN were washed in $0.1 \%$ PBS and incubated with $1 \%$ $\mathrm{H}_{2} \mathrm{O}_{2}$ to inactivate endogenous peroxidase. Sections then were sequentially incubated in the following solutions with buffer washes in between: (1) primary antibody (5A5, 3F4, or anti-VIP) diluted 1:500 with incubation buffer [50.0 mM Tris-buffered saline (TBS), $\mathrm{pH} 7.6$, containing $0.9 \%$ $\mathrm{NaCl}, 0.1 \%$ bovine serum albumin, and $0.1 \%$ Triton $\mathrm{X}-100]$ at $4{ }^{\circ} \mathrm{C}$ overnight; (2) corresponding secondary antibody conjugated with peroxidase (1:200) at room temperature for $1 \mathrm{hr}$; and (3) $0.02 \%$ diaminobenzidine (DAB) with $0.009 \% \mathrm{H}_{2} \mathrm{O}_{2}$ at room temperature for 5-10 min. Stained sections were floated onto a gel-coated slide, counterstained with a weak solution of methylene blue $(25 \mathrm{mg} / 500 \mathrm{ml} 30 \%$ ethanol), and mounted with coverslips with Permount (Fisher). Specificity of PSANCAM immunostaining was verified by (1) preincubation of sections for $1 \mathrm{hr}$ at room temperature with an endo $\mathrm{N}$, which specifically cleaves sialic acid polymers in chains of 7-9 or greater (Vimr et al., 1984); (2) adsorption of 5A5 antibody for $1 \mathrm{hr}$ at room temperature with immunoaffinitypurified polysialylated chicken NCAM $(50 \mu \mathrm{g} / \mathrm{ml})$; and (3) substitution of 5A5-containing ascites fluid with incubation buffer. Numbers of VIPimmunoreactive cell bodies in coronal planes representing the rostral, middle, and caudal SCN regions were counted at $400 \times$ magnification. Estimations of coronal plane areas defined by VIP immunostaining were undertaken using Image-Pro Plus software.

Immunoelectron microscopy. Brains from 60-d-old wild-type mice were processed for indirect antibody preembedding staining for immunoelectron microscopy as described (Seki and Arai, 1993), with the following modifications. Brain tissues were perfusion-fixed with $4 \%$ paraformaldehyde and $0.1 \%$ glutaraldehyde in phosphate buffer. Coronal vibratome sections containing the SCN were immunostained using a 1:500 dilution of monoclonal 5A5 ascites fluid overnight at $4^{\circ} \mathrm{C}$ followed by anti-mouse IgM conjugated to peroxidase for $2 \mathrm{hr}$ at room temperature. DAB was used as the chromogen. Immunostained sections were fixed in $1 \% \mathrm{OsO}_{4}$ in phosphate buffer, dehydrated, embedded in Epon 812 (Polysciences, Warrington, PA), and sectioned for standard transmission electron microscopy. Negative control sections were treated in parallel with the experimental sections but with no primary antibody or endo N. Thin sections were observed and photographed with and without counterstaining with lead citrate and uranyl acetate.

\section{Western immunoblot analyses}

Sample preparation. Under deep sodium pentobarbital anesthesia, mouse brains were removed, trimmed, and frozen on dry ice. Frozen $300-\mu \mathrm{m}-$ thick coronal sections of tissue containing the SCN were cut using a cryostat, and bilateral tissue punches (inner diameter of the punch $=0.80$ $\mathrm{mm}$ ) of the SCN hypothalamic region were made from the frozen sections using the optic chiasm and third ventricle as landmarks. The punches were stored at $-70^{\circ} \mathrm{C}$ before immunoblot analysis. After thawing, the tissues were sonicated in $20 \mathrm{vol}$ of Nonidet P-40 buffer $(0.5 \%$ Nonidet $\mathrm{P}-40$ in $0.1 \mathrm{M}$ PBS, pH 7.4) containing $20 \mu \mathrm{g} / \mathrm{ml}$ aprotinin (Sigma, St. Louis, MO) and centrifuged for $5 \mathrm{~min}$ at $13,600 \times \mathrm{g}$. An aliquot of supernatant from each sample was incubated with $1 \mu \mathrm{l}$ endo $\mathrm{N}$ for $2 \mathrm{hr}$ at $4^{\circ} \mathrm{C}$ to verify specificity of PSA-NCAM staining. The protein content of the supernatant was determined, and the supernatants were diluted with an equal volume of $2 \times$ concentrated sample buffer.

Electrophoresis and immunodetection. For PSA and NCAM determinations, an equal amount of total protein $(20 \mu \mathrm{g})$ from each sample was loaded on a $5 \%$ SDS-polyacrylamide gel, and proteins were separated electrophoretically. The PSA and NCAM were transferred to nitrocellulose membranes (Hybond-ECL, Amersham, Arlington Heights, IL) at 35 $\mathrm{V}$ for $18 \mathrm{hr}$. The membranes for PSA and NCAM staining, after airdrying, were incubated in 5\% dry milk dissolved in $20 \mathrm{~mm}$ TBS with $0.1 \%$ Tween-20 (TBS-T), $\mathrm{pH} 7.6$, for $4-6 \mathrm{hr}$ at $23^{\circ} \mathrm{C}$ to block nonspecific binding sites, and incubated in the TBS-T overnight at $4^{\circ} \mathrm{C}$. The PSA was detected by incubation with 5A5-containing ascites fluid diluted 1:500 with TBS-T overnight at $4^{\circ} \mathrm{C}$, and NCAM was detected by incubation with 3F4 antibody diluted to $1.77 \mu \mathrm{g} / \mathrm{ml}$ with TBS-T overnight at $4^{\circ} \mathrm{C}$. Both PSA and NCAM were visualized by incubating the nitrocellulose membranes with peroxidase-conjugated anti-mouse IgM and anti-mouse IgG secondary antibodies $(1 \mu \mathrm{g} / \mathrm{ml})$, respectively (Oreganon Teknika/Cappel Laboratories, Malvern, PA), and reacting the bound peroxidase with chemiluminescent substrate (ECL, Amersham). Chemiluminescence is detected by exposure to x-ray film (Hyperfilm-ECL, Amersham).

\section{In vivo endo $N$ injection}

Mice were anesthetized with pentobarbital (Nembutal, $85 \mathrm{mg} / \mathrm{kg}$ ) and received a stereotaxically guided $2 \mu$ injection of heat-inactivated (boiled) or active endo $\mathrm{N}$ via a 28 gauge cannula aimed at the $\mathrm{SCN}$ using the following coordinates: anteroposterior $=+2.2 \mathrm{~mm}$ from bregma; lateral $=1.3 \mathrm{~mm}$ from the midline at $5^{\circ}$ from vertical, and horizontal $=$ $4.5 \mathrm{~mm}$ from dura, with head level. The endo $\mathrm{N}$ used to remove PSA in this study was purified from bacteriophage K1F, as described by Hallenbeck et al. (1987).

\section{Experimental protocol}

A series of four sequential photoperiod trials were used to assess the effect of the $\mathrm{Ncam}^{\text {tm1Cwr }}$ mutation on circadian locomotor activity. For each experiment, age-matched male wild-type, heterozygous, and homozygous mutant litter mates were tested simultaneously in the same environmental chamber. The locomotor activity of wild-type $(n=12)$, heterozygous $(n=5)$, and homozygous $(n=15)$ Ncam $^{\text {tm1Cwr }}$ mutant mice was assessed under a regimen of $12 \mathrm{hr}$ light/dark (LD) (10 d), DD $(14 \mathrm{~d})$, LD $(10 \mathrm{~d})$, and LL $(13 \mathrm{~d})$. The free-running $\tau$ under DD was calculated over the last $10 \mathrm{~d}$ under DD. In a second experiment focused on the free-running activity rhythm, activity recordings of the wild-type $(n=3)$ and homozygous Ncam ${ }^{\text {tm1Cwr }}(n=11)$ mice were assessed under prolonged (6 weeks) exposure to DD. To study the effect of endo $\mathrm{N}$ removal of PSA on circadian activity, mice receiving a single intra-SCN endo $\mathrm{N}$ injection $6 \mathrm{~d}$ previously were exposed to DD for $12 \mathrm{~d}$, and the free-running $\tau$ was calculated over the last $10 \mathrm{~d}$ of DD. 


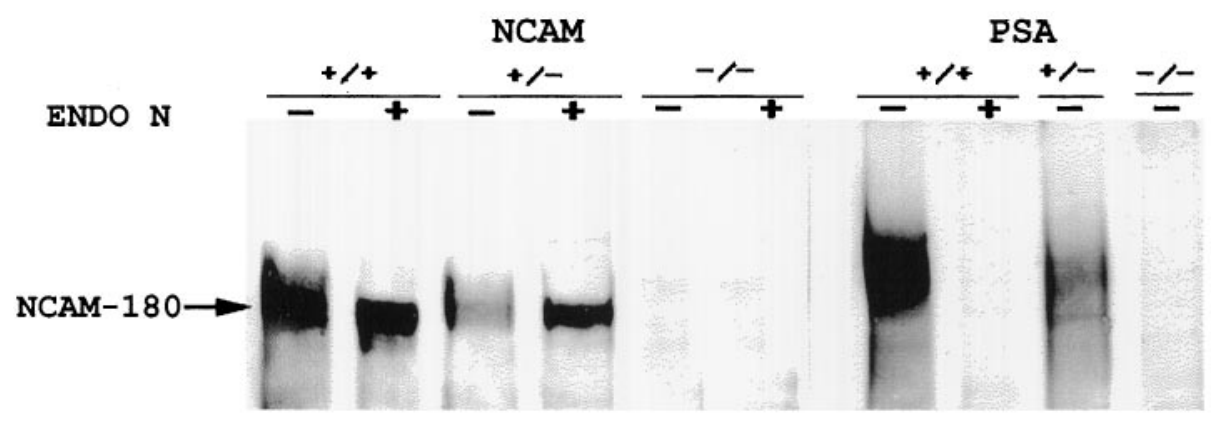

Figure 1. Immunoblot analyses of NCAM and PSA in wild-type $(+/+)$, heterozygous $( \pm)$, and homozygous $(-/-)$ Ncam $^{\text {tm1Cwr }}$ mutant SCN tissue. Preincubation of tissue extracts with endo $\mathrm{N}(E N D O N)$ was used to verify specificity of PSA immunostaining. Note the absence of staining for the $180 \mathrm{kDa}$ transmembrane NCAM isoform as well as PSA immunoreactivity associated with this isoform in the homozygous mutant. The preincubation with endo $\mathrm{N}$ notably enhanced staining for NCAM in heterozygote SCN extracts by allowing increased access of the anti-NCAM antibody to the NCAM. This effect was not evident in wild-type SCN extracts because of the much higher concentration of NCAM, which was intensely stained despite the presence of PSA.

\section{Statistics}

One-way ANOVA followed by the Student-Neuman-Keuls test was used to assess differences in rhythm period (tau) and activity duration $(\alpha)$ under DD. The level for statistical significance is $p<0.05$.

\section{RESULTS}

Mice homozygous for the $\mathrm{Ncam}^{\mathrm{tm} 1 \mathrm{Cwr}}$ mutation have been used previously to study NCAM and PSA in the olfactory bulb, subventricular zone, retina, and hippocampus (Tomasiewicz et al., 1993; Ono et al., 1994; Hu et al., 1996). In extending this analysis to the SCN, immunoblot and immunocytochemical analyses were performed on $\mathrm{Ncam}^{\mathrm{tm} 1 \mathrm{Cwr}}$ mutants to confirm the absence of the transmembrane NCAM-180 isoform and of the PSA, which is selectively associated with NCAM-180 in this region. As expected, the normally abundant expression of PSA-NCAM in wild-type mice was reduced in the heterozygous mutant and completely absent in the homozygous mutant (Figs. 1, 2). Ultrastructural analysis revealed specific immunostaining of selective regions of neuronal and glial plasma membranes within the SCN (Fig. 3). Positive immunostaining was evident on neuronal somata and processes as well as on fine glial processes interposed between neuronal components, but was also absent from adjacent regions of the same cells. No immunostaining was detected in the negative controls (no primary antibody or treatment with endo $\mathrm{N}$ ).

\section{Ncam $^{\text {tm1Cwr }}$ mutation disrupts circadian rhythmicity}

The circadian activity rhythms of wild-type $(+/+; n=12)$, heterozygous $( \pm ; n=5)$, and homozygous $(-/-; n=15)$ Nam $^{\text {tm1Cwr }}$ mutant mice were entrained to a defined LD cycle (Fig. 2). Under DD, the wild-type free-running activity rhythm was stable, with a $\tau$ of $\sim 24 \mathrm{hr}(23.9 \pm 0.05 \mathrm{hr})$ (Figs. 2, 4). In contrast, the free-running value of $\tau$ for the matched group of homozygous mutant litter mates was substantially shorter (23.5 \pm $0.09 \mathrm{hr} ; p<0.05$ ) (Figs. 2, 5, 6), and four homozygotes became arrhythmic immediately after initial exposure to DD. The freerunning $\tau$ of heterozygotes was intermediate in value but not significantly different from that of the wild-types or homozygotes $(23.7 \pm 0.15 \mathrm{hr})$.

A second characteristic of the $N$ cam $^{\mathrm{tm} 1 \mathrm{Cwr}}$ mutant phenotype was the shortening of the inactive period under DD caused by progressive lengthening of free-running activity (Fig. 7). The average duration of the nocturnal activity period under DD was $\sim 2$ hr longer than that of the wild-types $(p<0.05)$. After 2 weeks under DD, the majority $(\sim 75 \%)$ of homozygous mutant mice were active over the entire $24 \mathrm{hr}$ circadian day, which abolished the persistence of circadian rhythmicity. In contrast, the circadian activity rhythms of all wild types and heterozygotes remained intact. After subsequent exposure to LD, the locomotor activity rhythms of both the wild-type and heterozygote mice quickly reentrained to the $\mathrm{LD}$ cycle. The majority of homozygotes also rapidly reentrained to the $\mathrm{LD}$ cycle. Subsequent exposure to $\mathrm{LL}$ induced free-running locomotor activity characterized by a freerunning $\tau$ longer than $24 \mathrm{hr}$ and by imprecise activity onsets and offsets in mice of all genotypes.

The disruptive effect of the $N c a m^{\mathrm{tm} 1 \mathrm{Cwr}}$ mutation on freerunning locomotor activity was the focus of a second experiment, in which homozygous mutant $(n=11)$ and wild-type mice $(n=3)$ were tested under prolonged DD (45 d) (Fig. 8A). Consistent with our initial findings, the mutant free-running $\tau$ was substantially less than that of the wild types, and the duration of the inactive period was progressively shortened, which abolished circadian rhythmicity. Although the course of rhythm disruption was variable between individuals, all mutants (and none of the wild-type mice) became arrhythmic before the end of the DD treatment. When activity records of the arrhythmic mutant mice were plotted on shorter time scales, ultradian patterns with periodicities ranging between 3 and $9 \mathrm{hr}$ were evident (Fig. 8B). All genotypes became reentrained to the subsequent LD treatment.

\section{Enzymatic removal of PSA from the SCN affects circadian period}

From the extensive analysis of PSA-NCAM in developing systems, and the selective expression of PSA in particular adult brain regions, it is likely that at least part of the above effects on circadian rhythms reflects the unique influence of PSA on the plasticity of cell-cell interactions; however, the genetic perturbation of NCAM affects both PSA and the NCAM polypeptide. In an attempt to distinguish between these possibilities, analogous studies were performed using the PSA-specific endo N (Rutishauser et al., 1985, 1988). Immunohistological analyses of the time course of PSA depletion in the adult caused by intra-SCN microinjection of endo $\mathrm{N}$ confirmed that PSA expression in the $\mathrm{SCN}$ region was completely abolished for up to $18 \mathrm{~d}$ after treatment. Control injection of heat-inactivated endo $\mathrm{N}$ had no effect on PSA expression (data not shown). The inbred 129/Sv mice used for this experiment had a mean free-running $\tau$ that was $\sim 0.35 \mathrm{hr}$ longer than the Ncam ${ }^{\mathrm{tm} 1 \mathrm{Cwr}}$ wild types. As with the Ncam ${ }^{\mathrm{tm} 1 \mathrm{Cwr}}$ mutants, however, mice of the endo N-treated group had a significantly shortened free-running $\tau$ under DD compared with heat-inactivated endo N-treated controls (Figs. 9, 10) $(p<0.05)$. The magnitude of the endo $\mathrm{N}$-induced shortening of $\tau$ was nearly the same as that of the $N \operatorname{cam}^{\mathrm{tm} 1 \mathrm{Cwr}}$ phenotype $(\sim 0.4 \mathrm{hr}$ vs heat-inactivated endo $\mathrm{N}$ controls; $p<0.05$ ). 


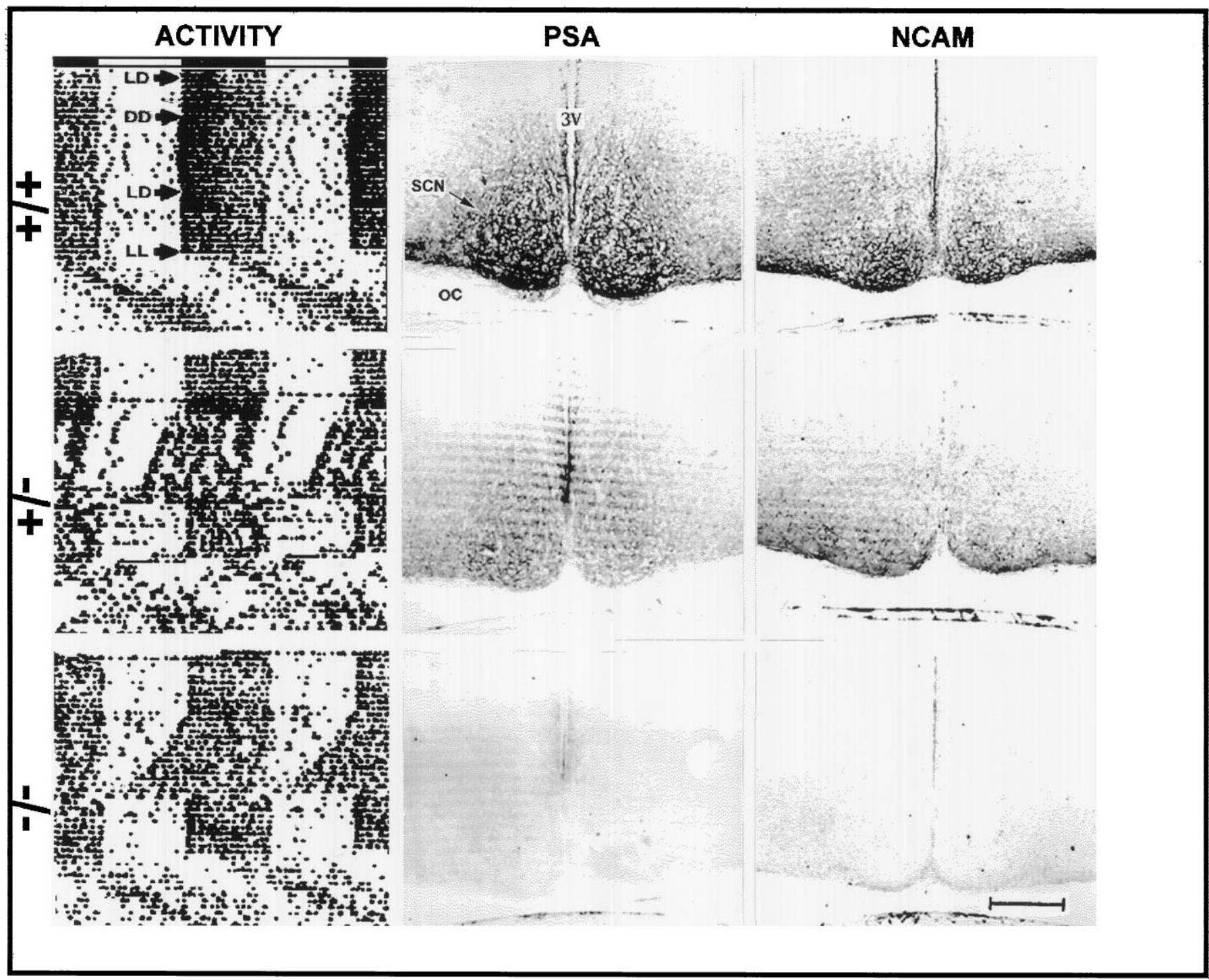

Figure 2. Left column, Representative profiles of the effects of $N$ cam ${ }^{\mathrm{tm} 1 \mathrm{Cwr}}$ mutation on circadian locomotor activity. Actograms are double-plotted such that each horizontal trace represents $48 \mathrm{hr}$, and the record of each day is presented to the right and beneath that of the preceding day. The horizontal bar above the actograms shows the day (clear) and night (shaded) portions of the LD cycle. Immunohistological staining of coronal sections containing the SCN for PSA and NCAM is presented in the middle and right columns, respectively. OC, Optic chiasm; $3 V$, third ventricle. Scale bar, $200 \mu \mathrm{m}$.

\section{Ncam ${ }^{\text {tm1Cwr }}$ mutation affects visible VIP- immunoreactive cell distribution in the SCN}

On the basis of estimates of the coronal plane area from VIPstained sections from the rostral, middle caudal aspects of the $\mathrm{SCN}$, there were no significant size differences between mutant and wild-type SCN (Fig. 11); however, VIP-immunoreactive cell counts from these three regions revealed marked dissimilarities in number and distribution of visibly stained cells between the mutant and wild type. The most striking differences were in the rostral and middle SCN, where the number of stained VIP cells was two- to threefold greater in the mutant as compared with the wild type (Fig. 12). Within all three regions, the majority of visible VIP-stained cells in the mutant were located in a more dorsomedial position as compared with the wild type (Fig. 13).

\section{DISCUSSION}

The findings that endogenous circadian locomotor activity of the homozygous $\mathrm{Nam}^{\mathrm{tm} 1 \mathrm{Cwr}}$ mutant phenotype was disrupted under DD suggest that the normal expression of NCAM is important for SCN time-keeping function. The primary role of polysialylated NCAM in neural tissues is believed to be the creation of permissive conditions for cell and axon rearrangements through the downregulation of contact-dependent cell interactions (Rutishauser et al., 1988; Landmesser et al., 1990; Ono et al., 1994; Tang et al., 1994; Yin et al., 1995; for review, see Rutishauser and Landmesser, 1996). With respect to the $\mathrm{SCN}$, the plasticity afforded by polysialylated NCAM could influence either the development of the SCN or its physiological function or both. The finding that enzymatic removal of PSA from the adult SCN mimicked the change in $\tau$ expressed by the mutant suggests that physiological processes are affected by the deletion of polysialylated NCAM. A developmental aspect is consistent with the increased number and altered distribution of visible VIP-immunoreactive neurons in the mutant SCN. In this regard, it is notable that VIP neurons have been implicated in SCN oscillator entrainment (Morin et al., 


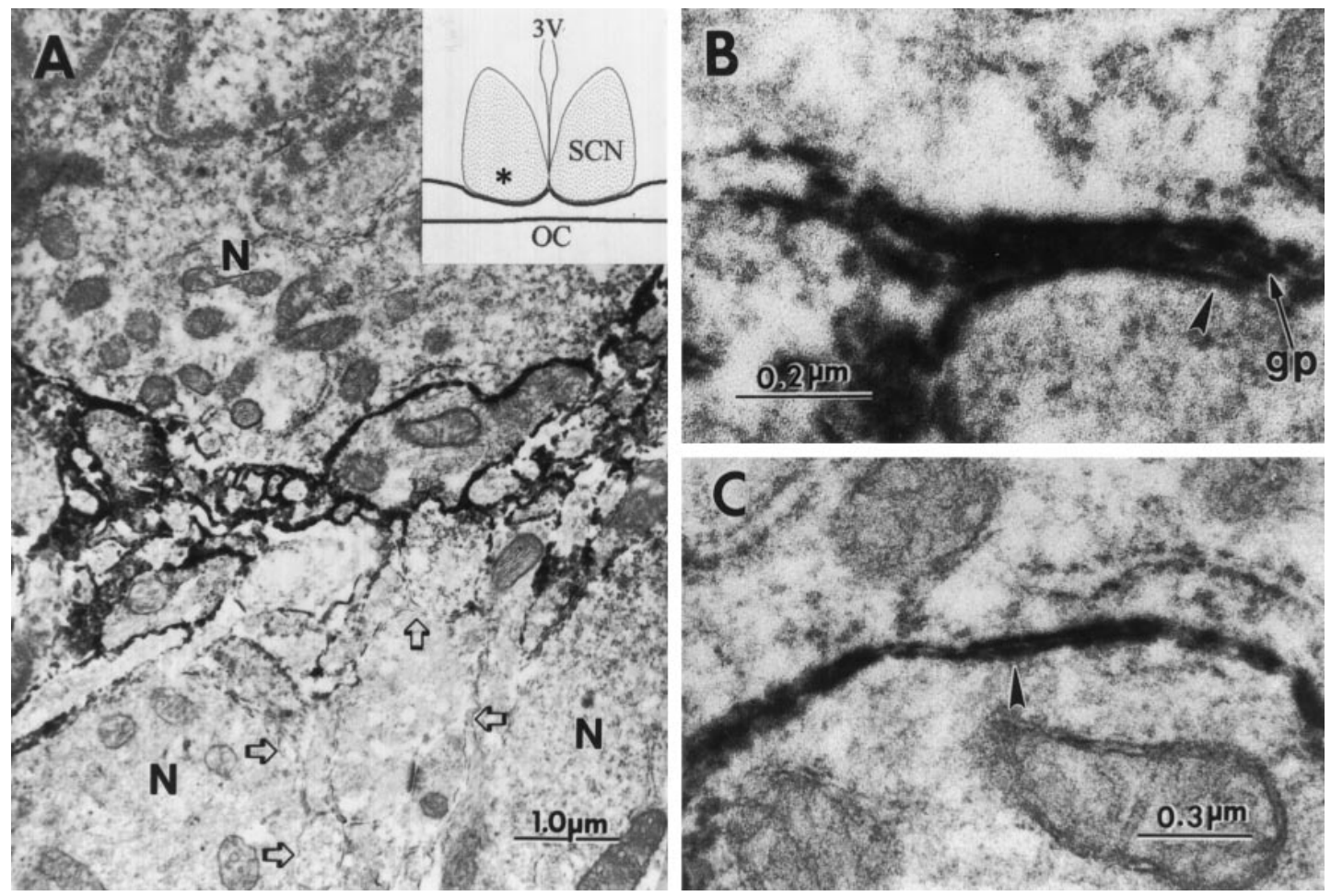

Figure 3. Electron micrographs of an anti-PSA immunoperoxidase-stained region of the SCN (indicated by asterisk in inset). Positive immunostaining for PSA-NCAM was evident on the plasma membranes of SCN neurons $(N)$ and processes $(A)$, at the interface between glial processes $(g p)$ and neurons $(B)$, and at the interface between neuronal components $(C)$. Regions of neuronal plasma membranes negative for PSA were present within the same region ( $A$, open arrows). Note the four-layered appearance of plasma membranes in $B$ where a glial process has intercalated between the neuronal soma and process (arrow). This can be compared with the two-layered appearance of plasma membranes in $C$ (arrowhead), where neurons are directly adjacent to each other with no intervening glial processes. $3 \mathrm{~V}$, Third ventricle; $O C$, optic chiasm; $n$, neuron; $g p$, glial process.
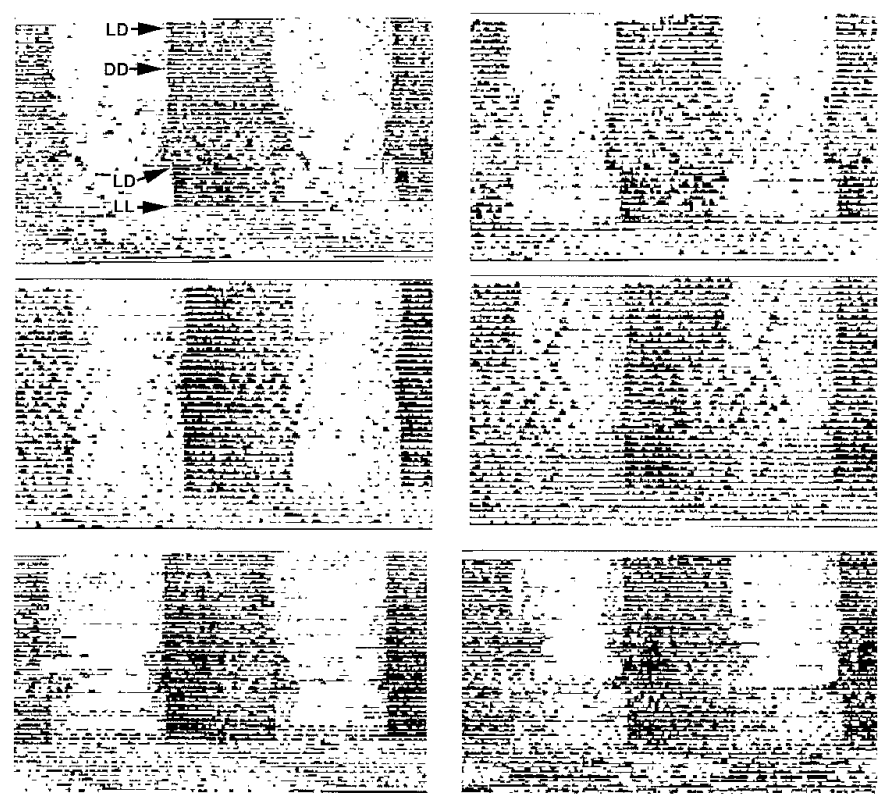

Figure 4. Activity profiles of six matched $N c a m^{\text {tm1Cwr }}$ wild-type litter mates of mutants shown in Figure 2. The majority of these animals maintained stable free-running circadian rhythmicity under DD.

1994), and that the mutant entrains to LD as well as the wild type, suggesting that entrainment is unhampered by the abnormal distribution of visible VIP-immunoreactive neurons. It is nevertheless possible that the organization of other SCN neural
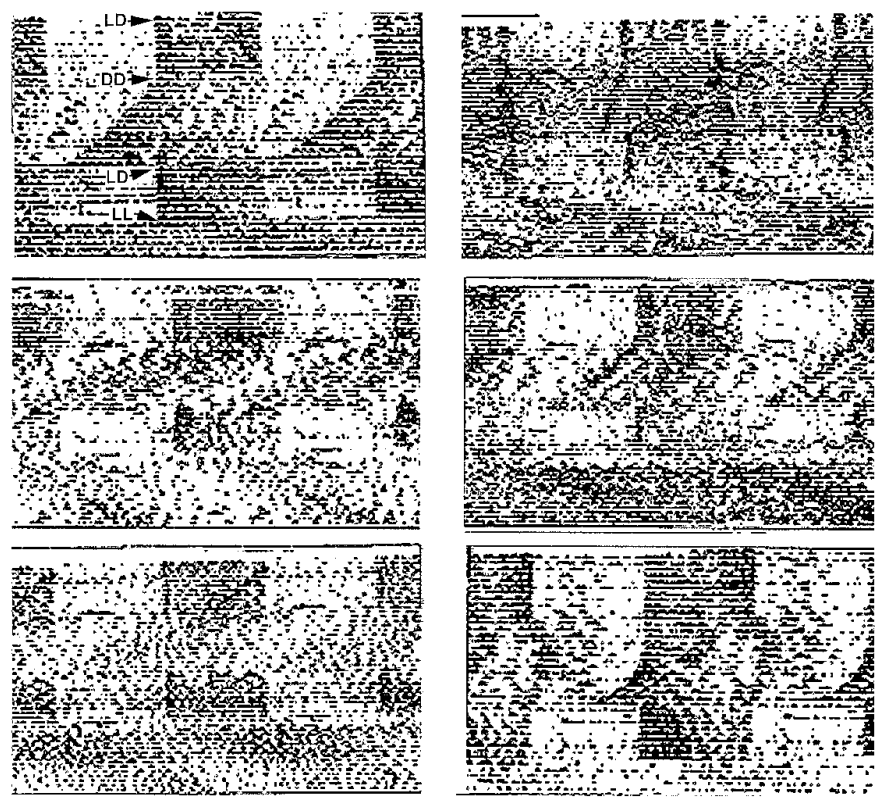

Figure 5. Activity profiles of six Ncam ${ }^{\text {tm1Cwr }}$ homozygous mutants from the same experiment as detailed in Figure 2. Note the disruptive effects of DD exposure on circadian rhythmicity.

systems may be affected by the $N$ cam $^{\text {tm1Cwr }}$ mutation, which could affect circadian clock function.

The function of polysialylated NCAM in the adult SCN may be to facilitate plastic neural interactions between cellular elements 


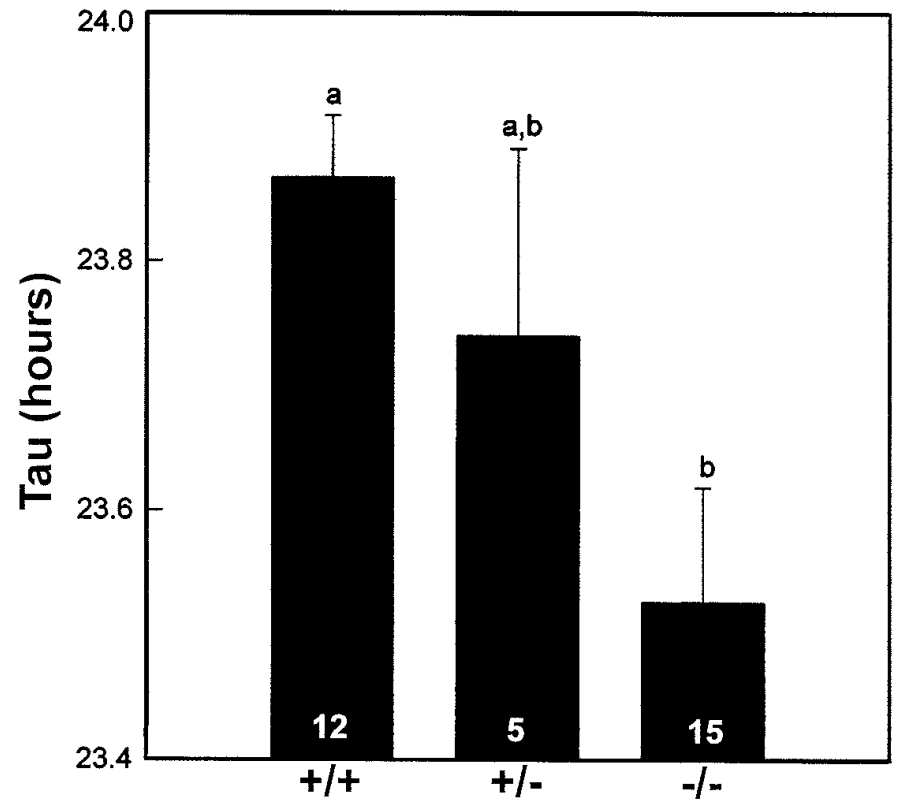

Figure 6. Effect of the Ncam ${ }^{\text {tm1Cwr }}$ mutation on the period (Tau) of the free-running locomotor activity rhythm averaged over the $10 \mathrm{~d}$ period under DD. The numbers in the bars indicate the number of mice in each group. Bars with different letters are significantly different; $p<0.05$.

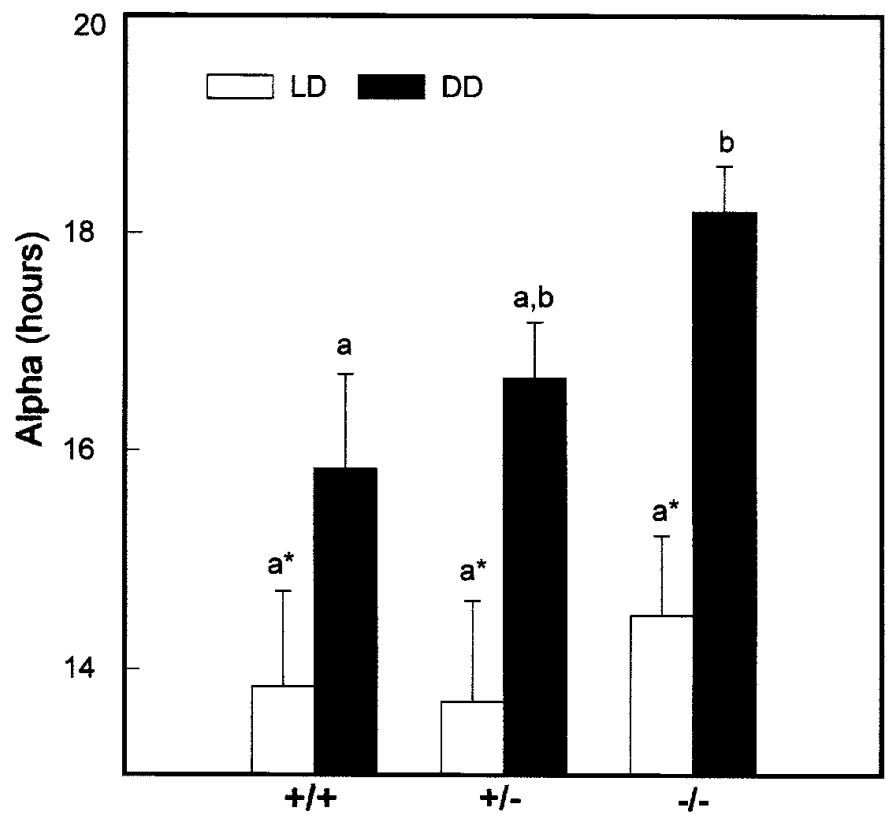

Figure 7. Effect of the $\mathrm{Ncam}^{\mathrm{tm} 1 \mathrm{Cwr}}$ mutation on the duration of activity $(\alpha)$ averaged over the $10 \mathrm{~d}$ period under DD for the same groups of mice shown in Figure 6. Vertical lines are SEM. Bars with different letters are significantly different; $p<0.05$.

of the circadian clock. Such interactions could be analogous to the neuronal-neuronal and/or neuronal-glial restructurings observed in the PSA-NCAM-rich paraventricular and supraoptic nuclei in response to various forms of physiological stimulation (Theodosis et al., 1991; Bonfanti et al., 1992). In this regard, it is significant that PSA expression in the SCN is evident at both neuron-neuron and neuron-glial interfaces, including cell somata as well as processes (Shen et al., 1996). Although additional studies will be needed to clarify the precise distribution of the PSA, the nature of

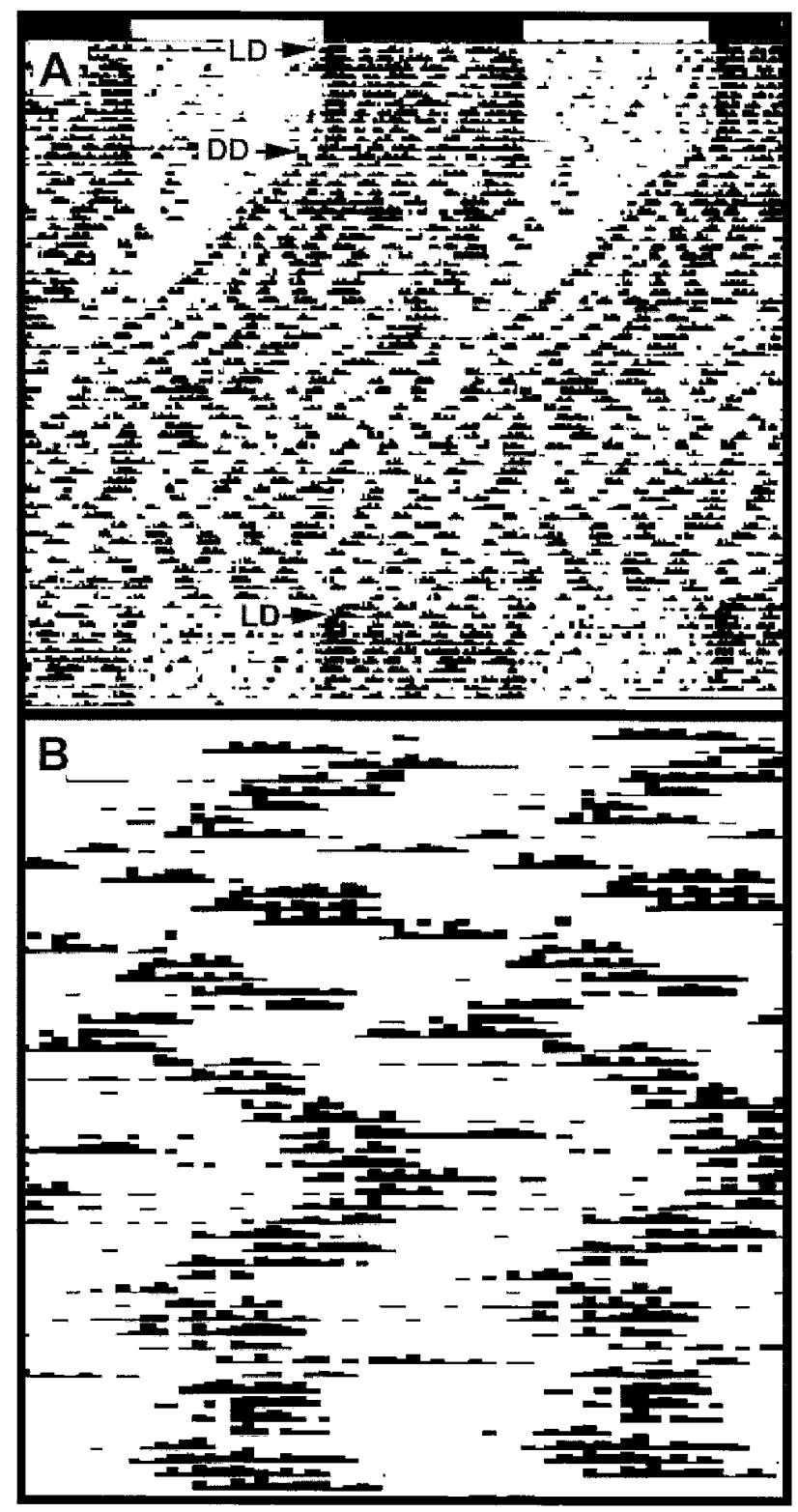

Figure 8. Effect of the Ncam ${ }^{\text {tm1Cwr }}$ mutation on circadian locomotor activity under prolonged constant darkness $(D D)$. $A$, Representative actogram of a homozygous mutant mouse under DD for $45 \mathrm{~d}$. This treatment resulted in a progressive shortening of the inactive period, which ultimately abolished circadian rhythmicity. $B$, The same activity record of the last $7 \mathrm{~d}$ of DD replotted on a time scale of $3.1 \mathrm{hr}$. This manipulation revealed a strong ultradian component for the majority of the mutant mice. Both actograms are double-plotted as in Figure 2. $L D$, Light/dark.

its effects at the cellular and circadian behavioral levels raises the intriguing possibility that PSA-NCAM may help regulate the degree of coupling between multiple SCN cells and/or oscillators that is thought to facilitate cohesive circadian patterns of signaling from the SCN clock.

There have been previous reports of mutant genes that influence mammalian circadian clock activity via identified products. Two examples are the recessive murine albino and pink-eyed dilution mutations associated with reductions or total loss of retinal melanin, which reportedly cause a shortening of $\tau$ under DD versus pigmented controls [Possidente et al., 1982; (although the pink-eyed dilution more recently was found to have no effect 


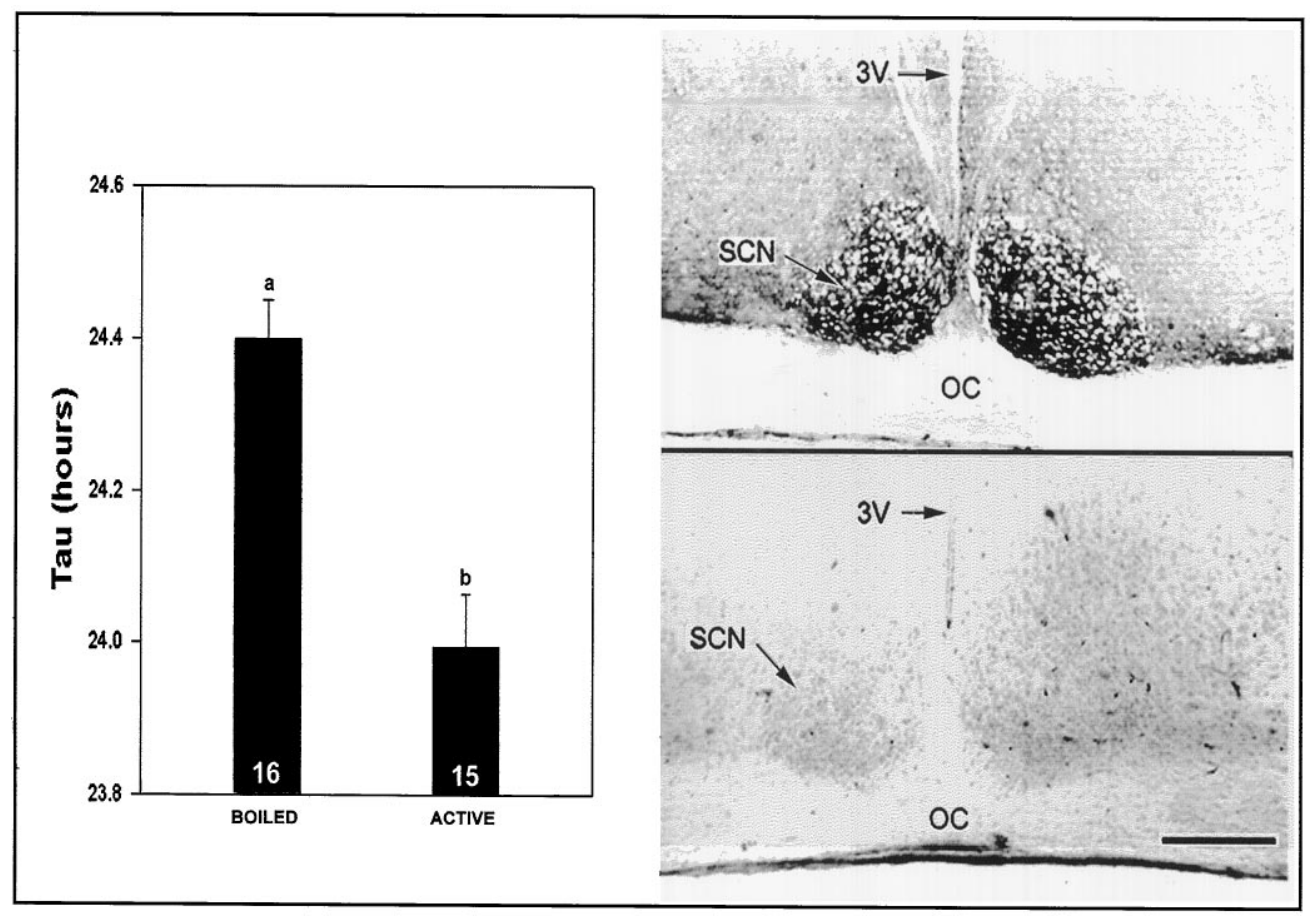

Figure 9. Left, Effect of enzymatic PSA removal on SCN clock function. After $10 \mathrm{~d}$ under $\mathrm{LD}$, mice received a microinjection of inactivated (BOILED; $n=$ $16)$ or active endo $\mathrm{N}(n=15)$. Six days after the injection, the mice were exposed to DD for $12 \mathrm{~d}$, and the freerunning period was averaged over the last $10 \mathrm{~d}$ of DD. Right, Immunostaining for PSA in mice treated with boiled (top) or active endo $\mathrm{N}$ (bottom) $14 \mathrm{~d}$ after endo $\mathrm{N}$ injection. $3 \mathrm{~V}$, Third ventricle; $O C$, optic chiasm. Scale bar, 150 $\mu \mathrm{m}$.
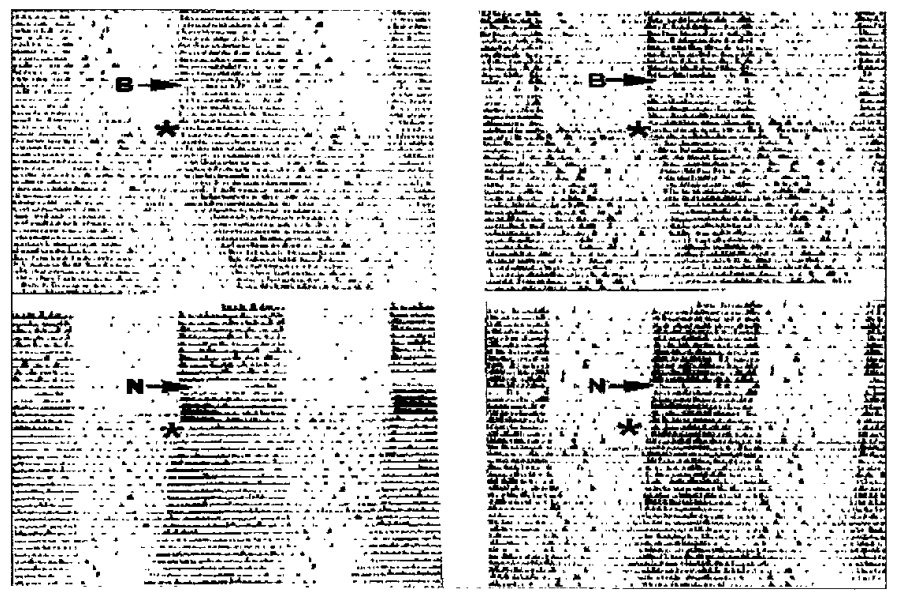

Figure 10. Top, Actograms of control mice that received boiled endo $\mathrm{N}$ $(B) 6 \mathrm{~d}$ before 4 weeks of DD exposure $(*)$. Bottom, Actograms of mice that received active endo $\mathrm{N}(N)$ before DD exposure. Mice of both groups were well entrained to the LD cycle $6 \mathrm{~d}$ preceding DD exposure. Note the $\tau$-shortening effect of the endo $\mathrm{N}$ treatment versus controls.

on free-running $\tau$; Vitaterna et al., 1993)]. Two other mammalian mutations affecting circadian clock function are tau (Syrian hamster; Ralph and Menaker, 1988) and clock (mouse; Vitaterna et al., 1994); however, the associated gene products have not been identified. There are certain behavioral similarities between the Ncam $^{\text {tm1Cwr }}$ phenotype and these other mutants. For example, each exhibits circadian activity rhythms that are entrained to the LD cycle, but each has aberrant free-running circadian $\tau$ under DD. Also, as with $\mathrm{Ncam}^{\mathrm{tm} 1 \mathrm{Cwr}}$, the circadian activity rhythm in clock mutants is lost under DD, albeit not by progressive shortening of the inactive period as in the $\mathrm{Ncam}^{\text {tm1Cwr }}$ homozygotes. Despite these similarities, however, it is unlikely that the albino, pink-eye, or clock related effects are directly related to the NCAM gene: pigment mutations are located on chromosome 1 , clock is

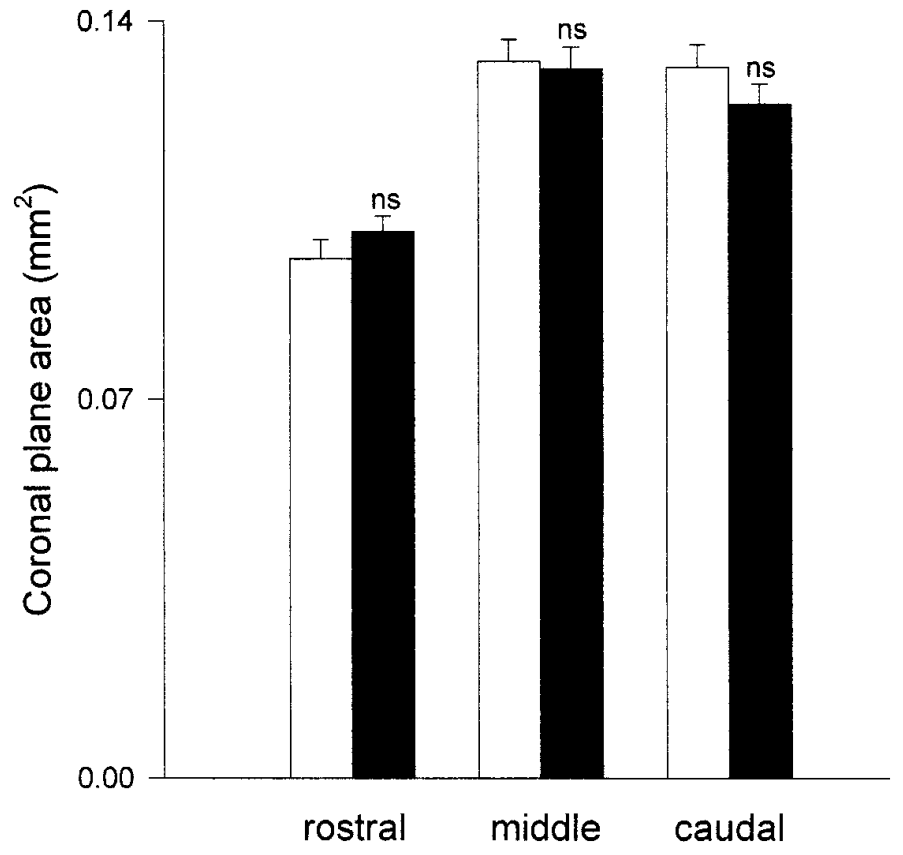

Figure 11. Areas of coronal plane rostral, middle, and caudal sections of SCN defined by VIP immunoreactivity. On the basis of these estimations, there was no apparent difference in volume of mutant (dark bars) versus wild-type SCN (clear bars). $n s$, Not significantly different from wild type ( $n=4$ mice/group). Vertical lines are SEM.

on chromosome 5, and the NCAM locus is on chromosome 9. The chromosomal location of tau is not yet known.

It has become increasingly evident that behavioral results from genetic disruption experiments such as those reported herein should be interpreted cautiously with respect to differences in genetic background and/or regions flanking the targeted mutation contributing to the phenotype (Gerlai, 1996; Lathe, 1996). For example, pronounced differences in free-running circadian 


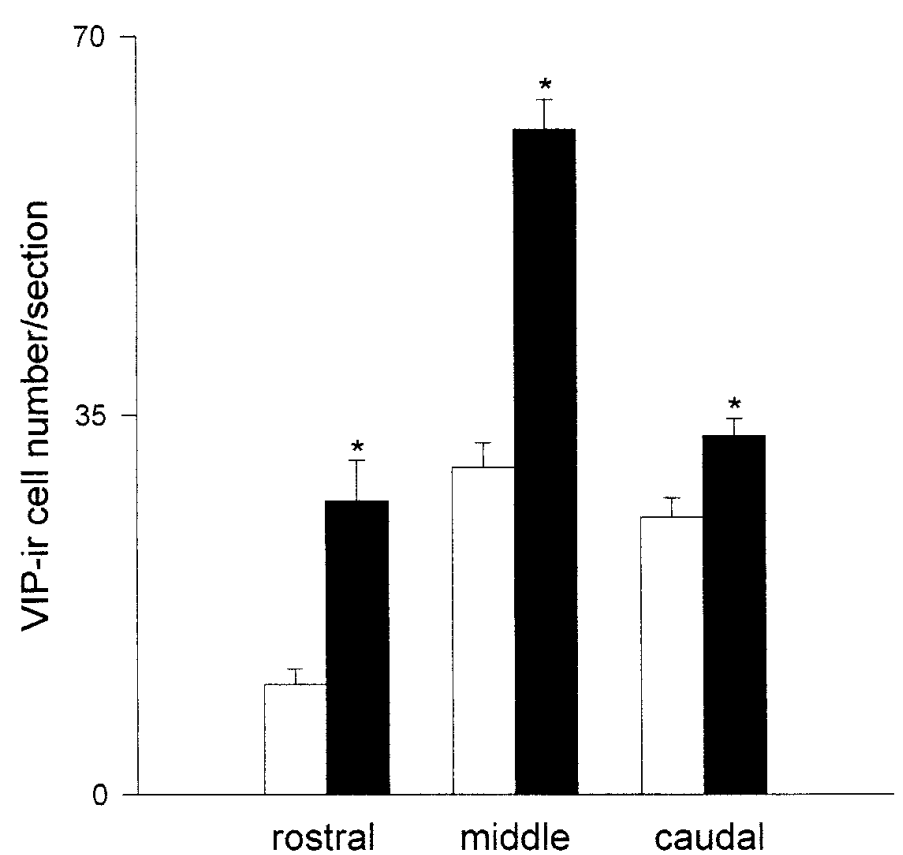

Figure 12. Number of VIP-immunoreactive cell bodies in coronal rostral, middle, and caudal sections of mutant (dark bars) versus wild-type SCN (clear bars). Asterisks denote significant difference between mutant and wild type for a given region $(p<0.05)$. Vertical lines are SEM.

rhythm $\tau$ and degree of stability are observed between various inbred murine strains under DD (Ebihara et al., 1978; Schwartz and Zimmerman, 1990; Rosenwasser, 1990). For a number of reasons, however, we believe that the circadian disruption observed in the $\mathrm{Ncam}^{\mathrm{tm} 1 \mathrm{Cwr}}$ mutants in the present study is solely attributable to the PSA-NCAM deletion. First, background differences are unlikely, given that the circadian disruption is associated only with the Ncam ${ }^{\mathrm{tm} 1 \mathrm{Cwr}}$ mutant mice. Second, flanking $129 / \mathrm{Sv}$ alleles linked to the NCAM locus on chromosome 9 producing circadian disruption are probably not a factor, because homozygous 129 /Svs used in the endo $\mathrm{N}$ injection experiment exhibited a stable free-running circadian activity rhythm under DD, with a value of $\tau$ being longer than that of the $\mathrm{Ncam}^{\mathrm{tm} 1 \mathrm{Cwr}}$ mutants. Third, the experimental design of this study minimized any age, sex, and environment-related differences between homozygous $\mathrm{Ncam}^{\mathrm{tm} 1 \mathrm{Cwr}}$ mice and the wild-type controls through the use of age-matched male litter mates tested simultaneously in the same environmental chamber.

The retina and olfactory bulb, which are known to be affected by the $\mathrm{Ncam}^{\text {tm1Cwr }}$ mutation (Tomasiewicz et al., 1993), also provide regulatory input to the SCN. Thus, it is possible that the brain locus for the disruptive effect of this mutation on circadian behavior may not be restricted to the SCN. In the retina, which supplies direct photic entraining information to the SCN (Moore and Lenn, 1972; Pickard, 1982; Johnson et al., 1988), homozygous Ncam $^{\text {tm1Cwr }}$ mice exhibit deformations of the inner nuclear and plexiform layers. Nevertheless, mutant retinal input to the SCN is sufficient for the normal entrainment of pacemaker activity, as evidenced by the maintenance of well entrained circadian locomotor activity rhythms under initial LD as well as the rapid reentrainment from DD back to LD. The $\mathrm{Ncam}^{\mathrm{tm} 1 \mathrm{Cwr}}$ mutation also inhibits migration of cells into the olfactory bulb, resulting in a reduced number of granule cells (Tomasiewicz et al., 1993). Because olfactory bulbectomy is known to affect the free-running

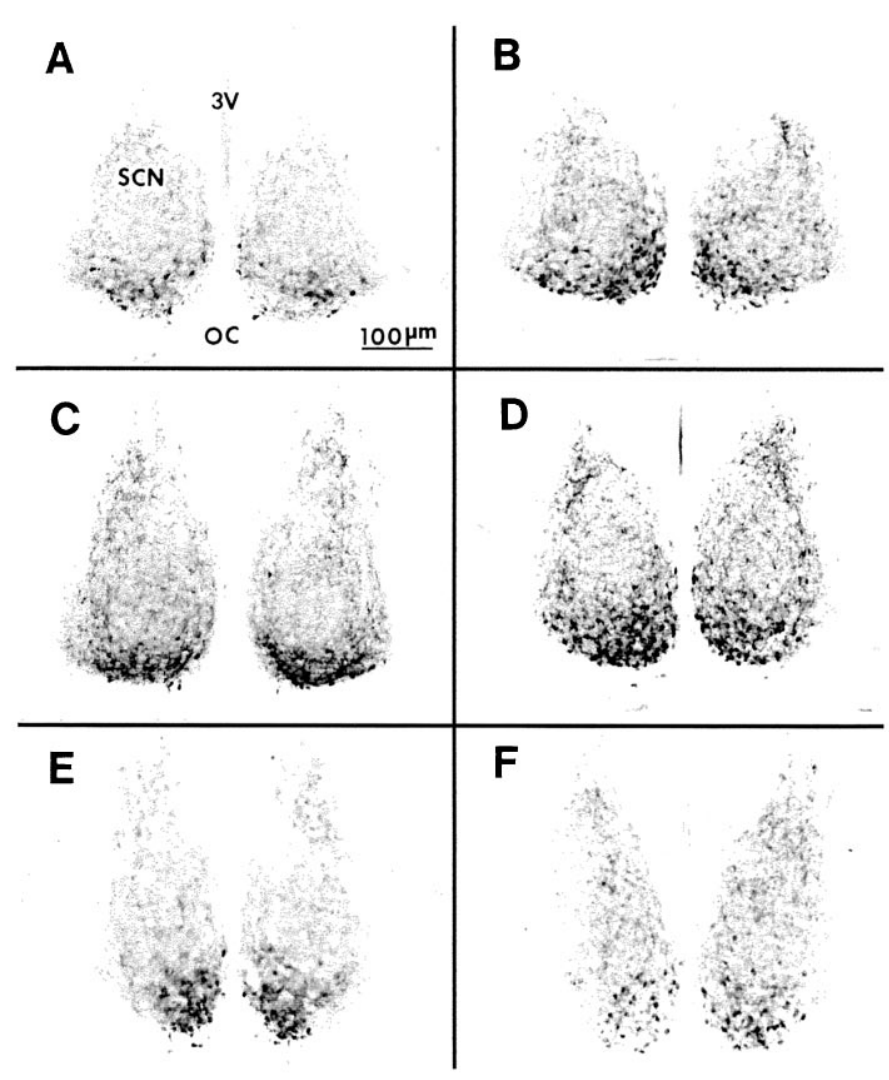

Figure 13. Photomicrographs of VIP immunostaining in wild-type ( $A, C$, $E)$ and mutant $(B, D, F)$ coronal sections containing rostral $(A, B)$, middle $(C, D)$, and caudal $(E, F) \mathrm{SCN}$ regions. Note the higher density of stained cells in the mutant middle $\mathrm{SCN}$ region. $3 \mathrm{~V}$, Third ventricle; $O C$, optic chiasm.

period of circadian activity in mice (Possidente et al., 1990), an olfactory bulb dysfunction in the mutant mice could potentially alter circadian clock function. Because the bulbectomized mice exhibit a persistent and stable free-running circadian locomotor rhythm with lengthened $\tau$ under DD, however, impaired olfactory bulb function is not likely to be the cause of the severe circadian disruption seen in the Ncam ${ }^{\mathrm{tm} 1 \mathrm{Cwr}}$ mutants.

The present results are the first to directly implicate PSA in the regulation of the mammalian circadian clock. How PSA exerts this action is speculative, but in the adult SCN the mechanism(s) involved could be analogous to those recently examined in the hippocampus using methodologies similar to those in the present study (Muller et al., 1996). These authors demonstrated that treatment of neonatal hippocampal slices with endo $\mathrm{N}$ completely prevented induction of two neurophysiological correlates of memory: long-term potentiation and long-term depression. Moreover, slices from NCAM-deleted mutants exhibited weak long-term potentiation. These results suggest that PSA and NCAM are required for synaptic plasticity. Whether PSA exerts a similar type of action in the SCN is as yet unknown; however, it is notable that the developing SCN has been shown to exhibit long-term depression related to cellular memory (Obrietan and van den Pol, 1996).

\section{REFERENCES}

Acheson A, Sunshine J, Rutishauser U (1991) NCAM polysialic acid can regulate both cell-cell and cell-substrate interactions. J Cell Biol 114:143-153.

Bonfanti L, Olive S, Poulain DA, Theodosis DT (1992) Mapping of the distribution of polysialylated neural cell adhesion molecule throughout 
the central nervous system of the adult rat: an immunohistochemical study. Neuroscience 49:419-436.

Card JP, Moore RY (1989) Organization of lateral geniculatehypothalamic connections in the rat. J Comp Neurol 284:135-147.

Cremer H, Lange K, Christoph A, Plomann M, Vopper G, Roes J, Brown R, Baldwin S, Kraemer P, Scheff S (1994) Inactivation of the N-CAM gene in mice results in size reduction of the olfactory bulb and deficits in spatial learning. Nature 367:455-457.

Daan S, Pittendrigh CS (1976) A functional analysis of circadian pacemakers in nocturnal rodents. II. The variability of phase response curves. J Comp Physiol 106:253-266.

Earnest DJ, Sladek CD (1986) Circadian rhythms of vasopressin release from individual rat suprachiasmatic explants in vitro. Brain Res 382:129-133.

Earnest DJ, Sladek CD, Gash DM, Wiegand SJ (1989) Specificity of circadian function in transplants of the fetal suprachiasmatic nucleus. J Neurosci 9:2671-2677.

Ebihara S, Tsuji K, Kondo K (1978) Strain differences of the mouse's free-running circadian rhythm in continuous darkness. Physiol Behav 20:795-799.

Gerlai R (1996) Gene-targeting studies on mammalian behavior: is it the mutation or the background genotype? Trends Neurosci 19:177-182.

Glass JD, Lee W, Shen H, Watanabe M (1994) Expression of immunoreactive polysialylated neural cell adhesion molecule in the suprachiasmatic nucleus. Neuroendocrinology 60:87-95.

Green DJ, Gillette MU (1982) Circadian rhythms of firing rate recorded from single cells in the rat suprachiasmatic brain slice. Brain Res 245:198-200.

Hallenbeck PC, Vimr ER, Yu F, Bassler B, Troy FA (1987) Purification and properties of a bacteriophage-induced endo- $\mathrm{N}$-acetylneuraminidase specific for poly- $\alpha$-2,8-sialosyl carbohydrate units. J Biol Chem 262:3553-3561.

$\mathrm{Hu}$ H, Tomasiewicz H, Magnuson T, Rutishauser U (1996) The role of polysialic acid in migration of olfactory bulb interneuron precursors in the subventricular zone. Neuron 16:735-743.

Inouye ST, Kawamura H (1979) Persistence of circadian rhythmicity in a mammalian hypothalamic "island" containing the suprachiasmatic nucleus. Proc Natl Acad Sci USA 76:5962-5966.

Johnson RF, Moore RY, Morin LP (1988) Loss of entrainment and anatomical plasticity after lesions of the hamster retinohypothalamic tract. Brain Res 460:297-313.

Kornhauser JM, Mayo KE, Takahashi JS (1993) Immediate gene expression in a mammalian circadian pacemaker: the suprachiasmatic nucleus. In: Molecular genetics of biological rhythms (Young MW, ed), pp 271-307. New York: Marcel Dekker.

Landmesser L, Dahm L, Tang J, Rutishauser U (1990) Polysialic acid as a regulator of intramuscular nerve branching during embryonic development. Neuron 4:655-667.

Lathe R (1996) Mice, gene targeting and behavior: more than just genetic background. Trends Neurosci 19:183-186.

Le Gal La Salle G, Rougon G, Valin A (1992) The embryonic form of neural cell surface molecule (E-CAM) in the rat hippocampus and its reexpression on glial cells following kainic acid-induced status epilepticus. J Neurosci 12:872-882.

Lehman MN, Silver WR, Gladstone RM, Kahn RM, Gibson M, Bittman EL (1987) Circadian rhythmicity restored by neural transplant: immunocytochemical characterization of the graft and its interaction with host brain. J Neurosci 7:1626-1638.

Moore RY (1983) Organization and function of a central nervous system oscillator: the suprachiasmatic nucleus. Fed Proc 42:2783-2789.

Moore RY, Lenn NJ (1971) A retinohypothalamic projection in the rat. J Comp Neurol 146:1-14.

Morin AJ, Moyse E, Denoroy L, Jouvet M (1994) VIP binding sites in rat hypothalamus: nuclear distribution and daily variations. Peptides 15:117-123.

Muller D, Wang C, Skibo G, Toni N, Cremer H, Calaora V, Rougon G, Kiss JZ (1996) PSA-NCAM is required for activity-induced synaptic plasticity. Neuron 17:413-422.

Obrietan K, van den Pol AN (1996) Neuropeptide Y depresses GABAmediated calcium transients in developing suprachiasmatic neurons: a novel form of calcium long-term depression. J Neurosci 16:3521-3533.

Ono K, Tomasiewicz H, Magnuson T, Rutishauser U (1994) N-CAM mutation inhibits tangential neuronal migration and is phenocopied by enzymatic removal of polysialic acid. Neuron 13:595-609.

Pickard GE (1982) The afferent connections of the suprachiasmatic nu- cleus of the golden hamster with emphasis on the retinohypothalamic projection. J Comp Neurol 211:65-83.

Possidente B, Stephan FK (1988) Circadian period in mice: analysis of genetic and maternal contributions to inbred strain differences. Behav Gen 18:109-117.

Possidente B, Hegmann JP, Carlson L, Elder B (1982) Pigment mutations associated with altered circadian rhythms in mice. Physiol Behav 28:389-392.

Possidente B, Lumia AR, McGinnis MY, Teicher MH, deLemos E, Sterner L, Deros L (1990) Olfactory bulb control of circadian activity rhythm in mice. Brain Res 513:325-328.

Ralph MR, Menaker M (1988) A mutation of the circadian system in golden hamsters. Science 241:1225-1227.

Ralph MR, Foster RG, Davis FC, Menaker M (1990) Transplanted suprachiasmatic nucleus determines circadian period. Science 247:975-978.

Rea MA (1989) Light increases Fos-related protein immunoreactivity in the rat suprachiasmatic nuclei. Brain Res Bull 23:577-581.

Rosenwasser AM (1990) Circadian activity rhythms in BALB/c mice: a weakly-coupled circadian system? J Interdiscipl Cycle Res 21:91-96.

Rusak B (1977) The role of the suprachiasmatic nuclei in the generation of circadian rhythms in the golden hamster, Mesocricetus aratus. J Comp Physiol 118:145-164.

Rusak B, Zucker I (1979) Neural regulation of circadian rhythms. Physiol Rev 59:449-526.

Rutishauser U, Landmesser L (1996) Polysialic acid in the vertebrate nervous system: a promoter of plasticity in cell-cell interactions. Trends Neurosci 19:422-427.

Rutishauser U, Watanabe M, Silver J, Troy FA, Vimr ER (1985) Specific alteration of NCAM-mediated cell adhesion by an endoneuraminidase. J Cell Biol 101:1842-1849.

Rutishauser U, Acheson A, Hall AK, Mann DM, Sunshine J (1988) The neural cell adhesion molecule (NCAM) as a regulator of cell-cell interactions. Science 240:53-57.

Seki T, Arai Y (1991) The persistent expression of a highly polysialylated NCAM in the dentate gyrus of the adult rat. Neurosci Res 17:265-274.

Schwartz WJ, Zimmerman P (1990) Circadian timekeeping in BALB/c and C57BL/6 inbred mouse strains. J Neurosci 10:3685-3694.

Schwartz WJ, Zimmerman P (1991) Lesions of the suprachiasmatic nucleus disrupt circadian locomotor rhythms in the mouse. Physiol Behav 49:1283-1287.

Shen H, Watanabe M, Glass JD (1996) Ultrastructural distribution of polysialylated neural cell adhesion molecule (PSA-NCAM) in the suprachiasmatic nuclei of the adult mouse. Soc Neurosci Abstr 22:658.3.

Tang J, Rutishauser U, Landmesser L (1994) Polysialic acid regulates growth cone behavior during sorting of motor axons in the plexus region. Neuron 13:405-414.

Theodosis DT, Rougon G, Poulain DA (1991) Retention of embryonic features by an adult nervous system capable of plasticity: polysialylated neural cell adhesion molecule in the hypothalamo-neurohypophyseal system. Proc Natl Acad Sci USA 88:5494-5498.

Tomasiewicz H, Ono K, Yee D, Thompson C, Gordis C, Rutishauser U, Magnuson T (1993) Genetic deletion of a neural cell adhesion molecule variant (N-Cam-180) produces distinct defects in the central nervous system. Neuron 11:1163-1174.

Vimr E, McCoy RD, Vollger HF, Wilkison NC, Troy FA (1984) Use of prokaryotic-derived probes to identify polysialic acid in neonatal neuronal membranes. Proc Natl Acad Sci USA 81:1971-1975.

Vitaterna MH, Wu JC, Turek FW, Pinto LH (1993) Reduced light sensitivity of the circadian clock in a hypopigmented mouse mutant. Exp Brain Res 95:436-442.

Vitaterna MH, King DP, Chang A-M, Kornhauser JM, Lowrey PL, McDonald JD, Dove WF, Pinto LH, Turek FW, Takahashi JS (1994) Mutagenesis and mapping of a mouse gene, clock, essential for circadian behavior. Science 264:719-725.

Yin X, Watanabe M, Rutishauser U (1995) Effect of polysialic acid on the behavior of retinal ganglion cell axons during growth into the optic tract and tectum. Development 121:3439-3446.

Youngstrom TG, Nunez AA (1986) Comparative anatomy of the retinohypothalamic tract in photoperiodic and non-photoperiodic rodents. Brain Res Bull 17:485-492.

Zhang DX, Rusak B (1989) Photic sensitivity of geniculate neurons that project to the suprachiasmatic nuclei or the controlateral geniculate. Brain Res 504:161-164. 